\title{
Mathematical Modeling of a Fermilab Helium Liquefier Coldbox
}

\author{
M.G. Geynisman and R.J. Walker \\ Fermi National Accelerator Laboratory \\ P.O. Box 500, Batavia, Illinois 60510
}

December 1995

Submitted to the 16th International Cryogenic Engineering Conference, Kitakyushu, Japan, May 20-24, 1996. 


\section{Disclaimer}

This report was prepared as an account of work sponsored by an agency of the United States Government. Neither the United States Government nor any agency thereof, nor any of their employees, makes any warranty, express or implied, or assumes any legal liability or responsibility for the accuracy, completeness, or usefulness of any information, apparatus, product, or process disclosed, or represents that its use would not infringe privately owned rights. Reference herein to any specific commercial product, process, or service by trade name, trademark, manufacturer, or otherwise, does not necessarily constitute or imply its endorsement, recommendation, or favoring by the United States Government or any agency thereof. The views and opinions of authors expressed herein do not necessarily state or reflect those of the United States Government or any agency thereof. 


\title{
Mathematical Modeling of a Fermilab Helium Liquefier Coldbox
}

\author{
Michael G. Geynisman and Ronald J. Walker \\ Fermi National Accelerator Laboratory* \\ Batavia, Illinois, 60510, USA
}

\begin{abstract}
The Fermilab Central Helium Liquefier (CHL) facility is operated 24 hours-a-day to supply LHe at $4.6^{\circ} \mathrm{K}$ for the Fermilab Tevatron superconducting proton-antiproton collider Ring and to recover warm return gases. The centerpieces of the CHL are two independent cold boxes rated at 4000 liters/hour and 5400 liters/hour with $\mathrm{LN}_{2}$ precool. These coldboxes are Claude cycle and have identical heat exchangers trains, but different turbo-expanders. The Tevatron cryogenics demand for higher helium supply from CHL was the driving force to investigate an installation of an expansion engine in place of the Joule-Thompson valve. A mathematical model was developed to describe the thermo- and gas-dynamic processes for the equipment included in the helium coldbox. The model is based on a finite element approach, opposite to a global variables approach, thus providing for higher accuracy and conversion stability. Though the coefficients used in thermo- and gas-dynamic equations are unique for a given coldbox, the general approach, the equations, the methods of computations, and most of the subroutines written in FORTRAN can be readily applied to different coldboxes. The simulation results are compared against actual operating data to demonstrate applicability of the model.
\end{abstract}

\section{INTRODUCTION}

Supporting the world's largest proton/antiproton collider in high energy physics research, the Fermilab Tevatron cryogenic system consists of a hybrid system of a Central Helium Liquefier (CHL) feeding twenty four $1 \mathrm{~kW}$ satellite refrigerators through a $6.5 \mathrm{~km}$ transfer line and supplying the liquid helium for the superconducting magnets of the accelerator and liquid nitrogen for the thermo shielding [1]. The original CHL system was built in 1979 and consisted of the helium reliquefier plant with one 4000 liters/hour helium liquefier (Coldbox-I) and two reciprocating compressors (Compressor A, B) [2]. Over the years of operations, general upgrades were made to improve the availability of the system, including an addition of a third helium compressor (Compressor $\mathrm{C}$ ) and 64,000 liters of liquid helium storage [3]. However, a significant impact on the accelerator physics program due to a major CHL failure pointed out the need for the CHL redundancy. Another reason for the system upgrade was the Tevatron accelerator upgrade to $1 \mathrm{TeV}$ energy operations. This is accomplished via lower temperature operation of the magnet system with twenty four cold compressors. The net effect on the cryogenic system is the increase of the CHL load to 170 grams/second, which was beyond the capacity of the Coldbox-I system. Therefore the CHL system was upgraded to include the second cold box (Coldbox-II) and the fourth compressor (" $\mathrm{D}$ ") [5]. The fourth reciprocating compressor has an increased capacity to 750 grams/second. The Coldbox-II design is generally identical to Coldbox-I. It is tied to the common compressor suction and discharge headers in parallel with Coldbox-I. Both coldboxes have heat exchangers manufactured by ALTEK International, Inc. Coldbox-I has three oil bearing turbo-expanders manufactured by Sulzer Brothers, Ltd. Coldbox-II has three oil bearing turboexpanders manufactured by Atlas Copco Rotoflow Corp.[4].

Nevertheless, an additional increase in helium production is still desired provided that no major additional capital investment is needed. One of the logical solutions is to replace the JouleThompson (JT) valve, which is installed at the coldbox process point of final helium gas expansion,

\footnotetext{
- Operated by Universities Research Association, Inc. under contract with U.S. Department of Energy
} 
with an expansion engine. This solution is thermodynamically viable, though needs to be evaluated in terms of overall cycle efficiency and production increase versus required capital investment. Some helium liquefier facilities have reported this type of successful conversion in the past [5]. To evaluate this conversion, as well as to have a reliable simulation tool in the future, the authors have developed the mathematical model and implemented it in FORTRAN code. The model describes mathematically the thermodynamic processes in the coldbox equipment and final subcooler at steady-state conditions. The model is a set of non-linear algebraic equations, which describe the links between thermodynamic variables within the coldbox's flow paths. The FORTRAN code of the HEPAK of Cryodata Inc. is used in the model to calculate helium properties. The heat transfer in the coldbox's heat exchangers is computed by using the ALTEC plate-fin geometric data and a customized FEA method. In this method every heat exchanger (HTX) is considered as a set of sections of equal length with a known geometrical data and calculated mass and heat transfer properties. Each section is calculated separately, and then all sections are laced together through "in-out" variables. The non-isentropic gas expansion in the turbo-expanders is computed by using relationships for each turbine's efficiency versus its speed and flow, as per data provided by the turbines' manufacturer. The lacing of the variables along the coldbox's flow paths is accomplished to simulate the propagation of the parameters change due to variation in input variables. Any change in input variables, i.e. coldbox's flow, pressure, temperature, etc., results in coldbox transition to the new and unique set of thermodynamic conditions. The model allows for stable conversion to new conditions at $100 \%$ step change of any of the input variables. The overall heat balance of the coldbox is checked to determine the accuracy of conversion. The number of iterations to provide for accurate conversion is less then 10,000 .

\section{COLDBOX LAYOUT AND MODEL ASSUMPTIONS}

Coldbox-I and -II layouts are identical and shown on Figure 1 further in the text. Both coldboxes have one more 3-path heat exchanger not shown on Figure 1 and located on the warm end. This is a $\mathrm{LN}_{2}$-to-GHe precool heat exchanger. Though the pressure drops are the most significant for this heat exchanger, its helium gas exit temperature stays at the preset level due to fine regulation via temperature control loop. Therefore we excluded this heat exchanger from the coldbox model, but instead shifted the input variables one heat exchanger down the coldbox.

\section{Notations:}

- hw - notation for parameters at the high pressure path and warm end of a heat exchanger, i.e. thw

- hc - notation for parameters at the high pressure path and cold end of a heat exchanger, i.e. thc

- Iw - notation for parameters at the low pressure path and warm end of a heat exchanger, i.e. tlw

- Ic - notation for parameters at the low pressure path and cold end of a heat exchanger, i.e. tlc

- mw - notation for parameters at the mid pressure path and warm end of a heat exchanger, i.e. tmw

- $\mathrm{mc}$ - notation for parameters at the mid pressure path and cold end of a heat exchanger, i.e. tmc

Nomenclature:

- $\mathrm{t}$ - temperature, ${ }^{\circ} \mathrm{K}$

- $\quad$ - pressure, Pa

- $\mathrm{h}$ - enthalpy, $\mathrm{J} / \mathrm{kg}$

- $\mathrm{s}$ - entropy, $\mathrm{J} / \mathrm{kg}-\mathrm{K}$

- f - mass flow, $\mathrm{kg} / \mathrm{s}$

- $\rho$-density, $\mathrm{kg} / \mathrm{m}^{3}$

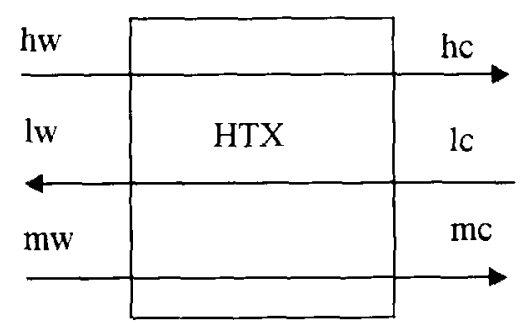


- acfm - actual volumetric flow, $\mathrm{ft}^{3} / \mathrm{s}$ or $\mathrm{m}^{3} / \mathrm{s}$

- rpm - rotation speed, revolutions per minute

- $\mu$ - viscosity, Pa-s

- $\mathrm{c}_{\mathrm{p}}$ - specific heat, $\mathrm{J} / \mathrm{kg}^{-}{ }^{\circ} \mathrm{K}$

- q-quality

- qh, qm, ql - heat transferred from high, middle, and to the low pressure paths, watt

- ac - cross section area of flow, $\mathrm{m}^{2}$

- $a w$ - wetted fin area, $\mathrm{m}^{2}$

- flen - effective length of the heat exchanger section and the plate fins, $m$

- de - equivalent diameter, $d_{e}=\frac{4 \cdot a c \cdot f l e n}{a w}, \mathrm{~m}$

- qloss - heat load from outside, watt

- tfin - temperatures of a fin, ${ }^{\circ} \mathrm{K}$

- hh, hm, hlh, hlm - heat transfer coefficients between bulk temperatures in the high path and tfïnh, mid path and tfinm, low path and tfinh, and low path and tfinm

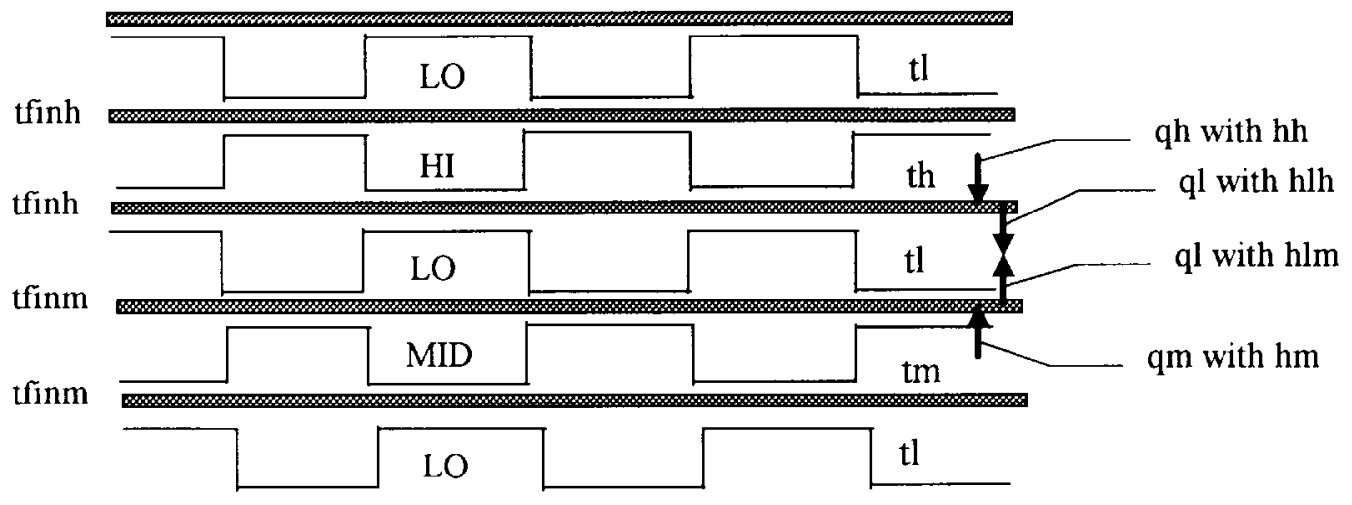

- assume that direct heat transfer from mid to high path is negligible. Then the heat transfer equations are:

$$
\begin{aligned}
& q l=q h+q m \\
& q h=A \cdot h h \cdot(t h-t \text { finh }) \\
& q m=A \cdot h m \cdot(t m-t \text { finm }) \\
& q l-\frac{A}{2} \cdot h l h \cdot(t \text { finh }-t l)+\frac{A}{2} \cdot h l m \cdot(t \text { finm }-t l)
\end{aligned}
$$

- the heat transfer coefficients $\mathrm{h}$ and the pressure drops $\Delta \mathrm{p}$ for the section of the length $\mathrm{dx}$ of the given heat exchanger are calculated with the well-known equations:

$$
\begin{array}{ll}
h=j_{t} \cdot c_{p} \cdot G \cdot(\operatorname{Pr})^{-2 / 3}, & \text { where: } \mathrm{G}=\mathrm{f} / \mathrm{ac}, \text { mass flow per unit of area } \\
\Delta p=f_{t} \cdot\left(d x / d_{e}\right) \cdot\left(G^{2} / \rho\right), & \text { where: } \operatorname{Pr}=\mathrm{c}_{\mathrm{p}} \mu / \mathrm{k}, \mathrm{k} \text { is thermal conductivity }
\end{array}
$$

The coefficients $j_{\mathrm{t}}$ and $f_{\mathrm{t}}$ are functions of Re number, where $\mathrm{Re}=\mathrm{d}_{\mathrm{e}} \mathrm{G} / \mu$. The numerical correlation between $j_{l}, f_{t}$ and Re are defined per manufacturer test data. In case of the Fermilab coldbox heat exchangers ALTEC provided the authors with the tabulated data for $j_{t}$ and $f_{t}$ vs. Reynolds numbers 
ranging from 40 to 40,000 for each type of its brazed aluminum plate-fin heat exchangers. Then the authors plotted the tabulated data and fitted it with exponential equations of the following type:

$$
\begin{aligned}
& j_{1}=a_{0}+a_{1} \cdot \exp \left(-\operatorname{Re} / b_{1}\right)+a_{2} \cdot \exp \left(-\operatorname{Re} / b_{2}\right)+a_{3} \cdot \exp \left(-\operatorname{Re} / b_{3}\right) \\
& f_{t}=c_{0}+c_{1} \cdot \exp \left(-\operatorname{Re} / d_{1}\right)+c_{2} \cdot \exp \left(-\operatorname{Re} / d_{2}\right)+c_{3} \cdot \exp \left(-\operatorname{Re} / d_{3}\right)
\end{aligned}
$$

- equations describing Atlas Copco Rotoflow Corp. turbo-expander are:

$$
\begin{aligned}
& \text { Peripheral blade tip speed at } \mathrm{n} \mathrm{rpm}, \mathrm{m} / \mathrm{sec}: \quad U=\frac{\pi}{} \\
& \text { The isentropic efficiency for expander: } \quad \eta_{e}=\frac{h_{1}-h_{2}}{h_{1}-h_{2}^{\prime}}
\end{aligned}
$$

Ideal expansion speed, $\mathrm{m} / \mathrm{s}: C_{o}=\sqrt{2 \cdot\left(h 1-h 2^{\prime}\right)}$

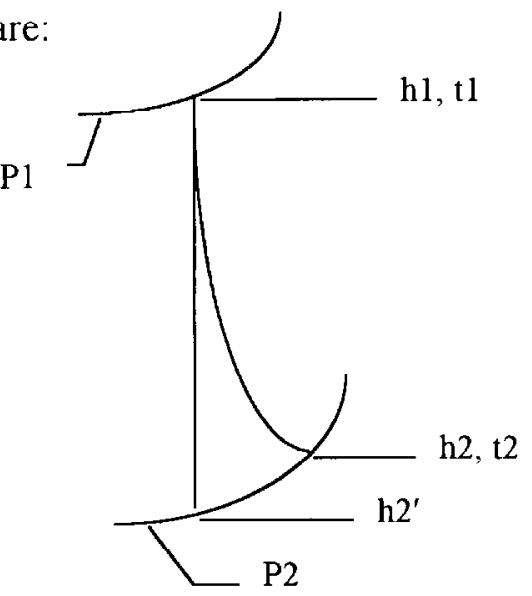

To obtain isentropic efficiency of the turbo-expander the authors have used the set of equations and graphical correlation between efficiency, speed and flow provided by Atlas Copco Rotoflow Corp. The equations are:

$\eta_{t o t}=\eta_{u}-\eta_{v}$, where $\eta_{u}$ is a function of $\mathrm{U} / \mathrm{C}_{0}$, and $\eta_{v}$ is a function of $(\mathrm{acfm} / \mathrm{rpm})^{\text {actual }} /(\mathrm{acfm} / \mathrm{rpm})^{\text {design }}$. Then the authors have fitted the graphical dependencies for $\eta_{u}$ and $\eta_{v}$ for each turbo-expander with 3 rd order polynomial equations.
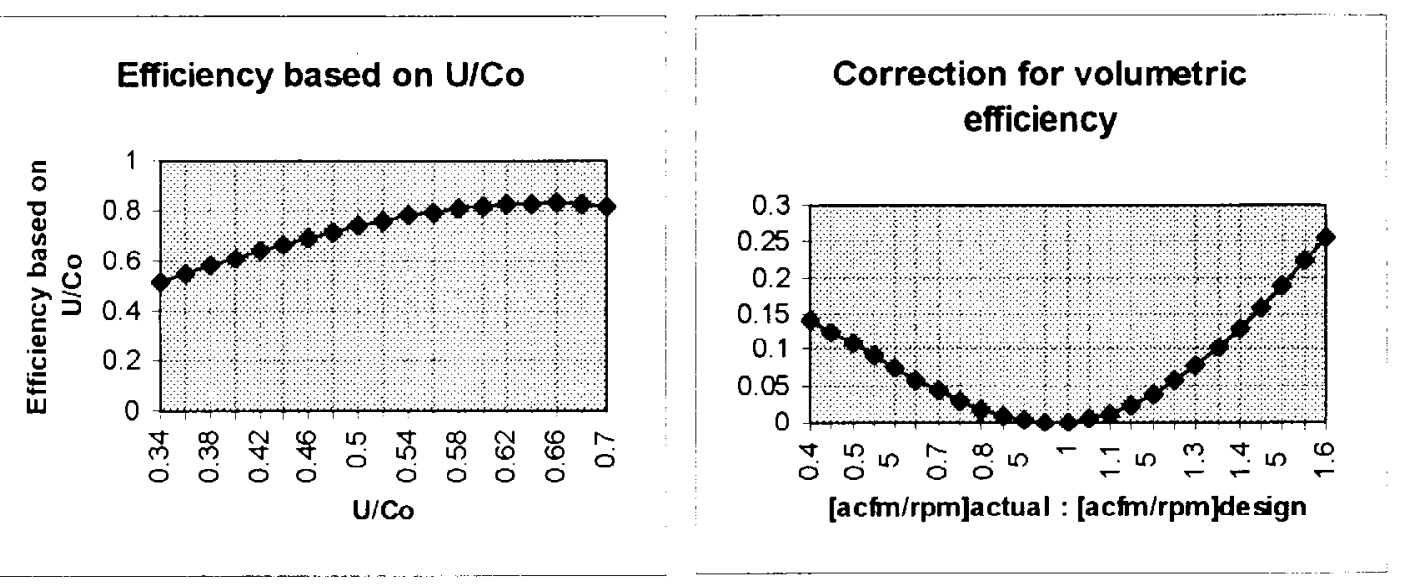

The actual speed of each turbo-expander is a function of its shaft power:

$n_{\text {actual }}=n_{\text {design }} \cdot\left[\frac{\text { Power }^{\text {actual }}}{\text { Power }^{\text {design }}}\right]^{1 / 2.8}=n_{\text {design }} \cdot\left[\frac{\left(f \cdot \Delta h \cdot \eta_{\text {tot }}\right)^{\text {actual }}}{\left(f \cdot \Delta h \cdot \eta_{\text {tot }}\right)^{\text {design }}}\right]^{1 / 2.8}$

The graphical representation of the model is shown below on Fig. 1 and 2 below. 


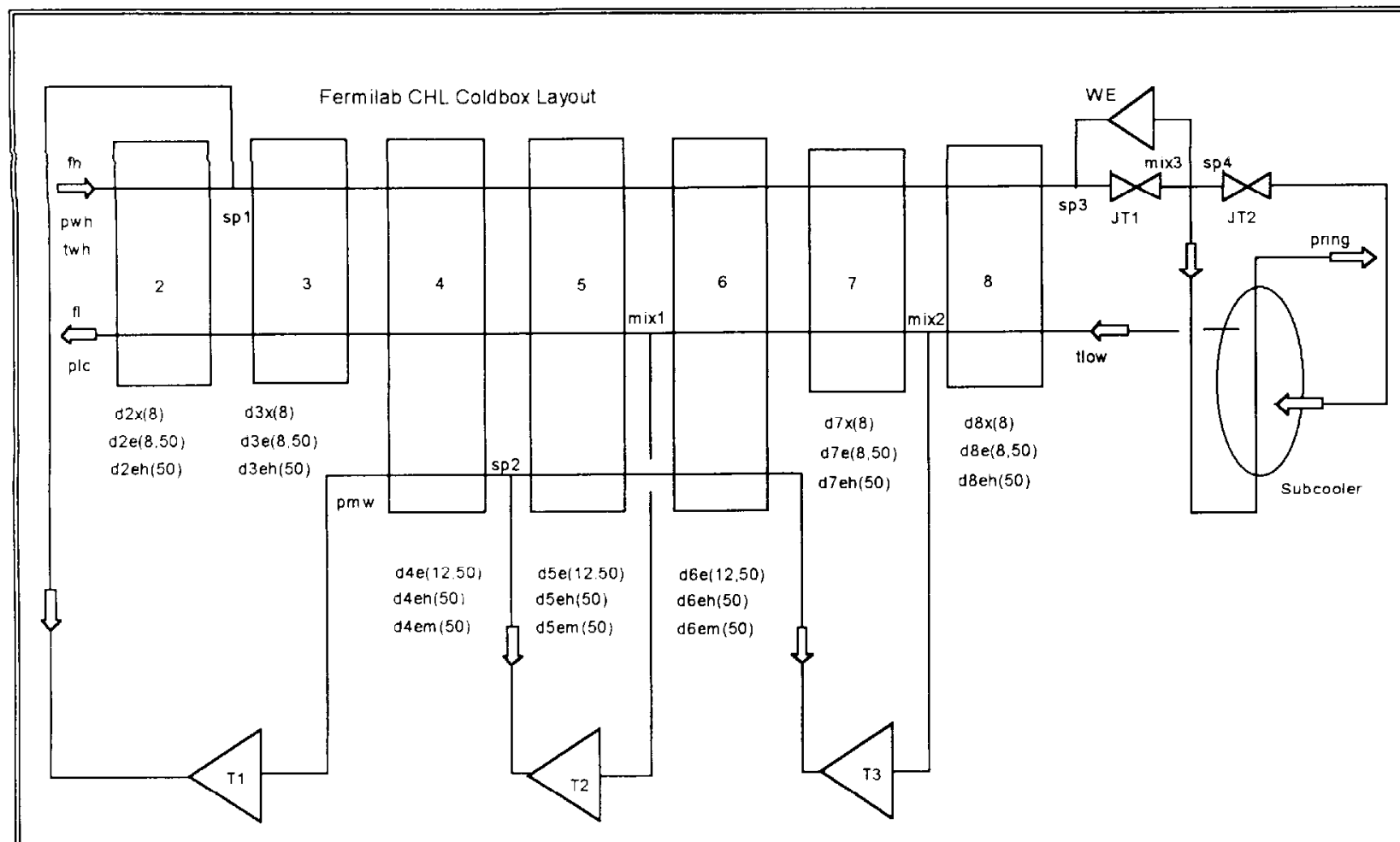

Fig. 1. Fermilab CHL Coldbox

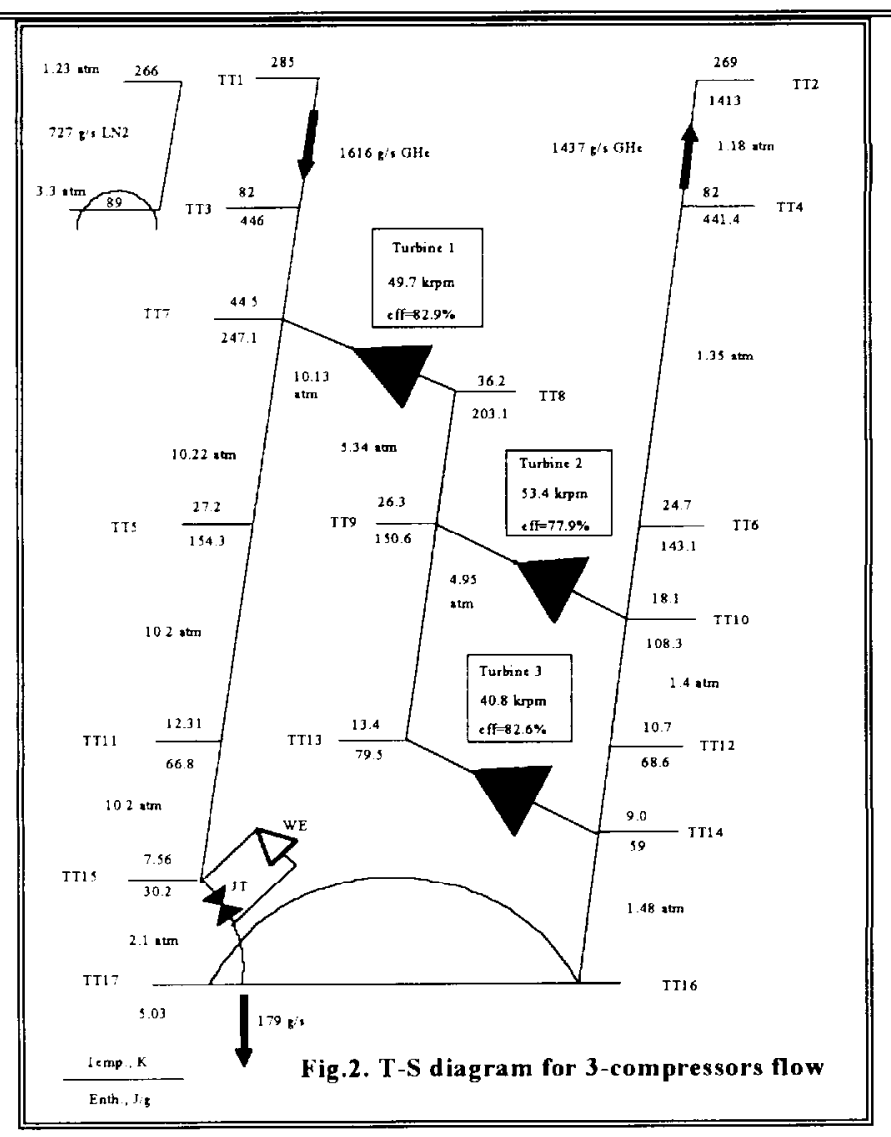


The model includes 7 heat exchangers, numbered as $n_{i}$ from $i=2$ to $i=8$. The number of cross-sections $\mathrm{k}$ for each heat exchanger can be set independently. Iteration results have shown that 50 cross-sections is sufficient for most heat exchangers, though the FORTRAN code allows to set that number up to 100.

The following array represents all process parameters for a 2-path heat exchanger, where $n_{i}=2,3,7,8$ :

\begin{tabular}{|c|c|c|c|c|c|c|c|c|}
\hline phw & thw & plw & tlw & phc & the & plc & tlc & tfin \\
\hline $\operatorname{dnt} \mathrm{e}(1,1)$ & $\operatorname{dn}_{\mathrm{i}} \mathrm{e}(2,1)$ & $\mathrm{dn}_{\mathrm{i}} \mathrm{e}(3,1)$ & $\mathrm{dn} \mathrm{e}(4,1)$ & $\mathrm{dn}_{\mathrm{i}} \mathrm{e}\left(5, \mathrm{k}_{\mathrm{i}}\right)$ & dnie $\left(6, \mathrm{ki}_{\mathrm{i}}\right)$ & $\operatorname{dn} \mathrm{e}\left(7, \mathrm{k}_{\mathrm{i}}\right)$ & $\operatorname{dn} \mathrm{e}\left(8, \mathrm{k}_{\mathrm{i}}\right)$ & $\operatorname{dn} i e h\left(k_{i}\right)$ \\
\hline
\end{tabular}

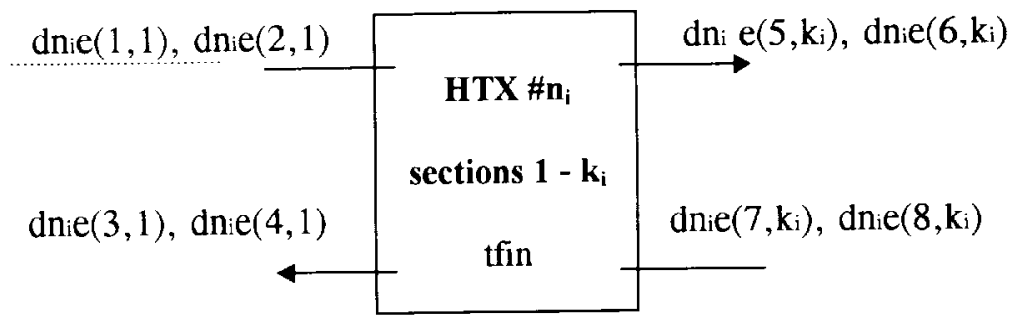

The following array represents all geometrical, heat loss and flow parameters for a 2-path heat exchanger, where $n_{i}=2,3,7,8$ :

\begin{tabular}{|c|c|c|c|c|c|c|c|}
\hline awh & awl & ach & acl & flen & qloss & fh & $\mathrm{fl}$ \\
\hline $\operatorname{dnlix}(1)$ & $\mathrm{dn}_{\mathrm{i}} \mathrm{x}(2)$ & $\operatorname{dn} x(3)$ & $\operatorname{dnix}(4)$ & $\mathrm{dn}_{\mathrm{x}} \mathrm{x}(5)$ & $\mathrm{dn} \mathrm{x}(6)$ & $\mathrm{dn}$ ix (7) & $\operatorname{dn}_{\mathrm{x}} \mathrm{x}(8)$ \\
\hline
\end{tabular}

The following array represents all process parameters for a 3 -path heat exchanger, where $n_{i}=4,5,6$ :

\begin{tabular}{|c|c|c|c|c|c|c|c|}
\hline phw & thw & pmw & tmw & plw & $\mathrm{tlw}$ & & \\
\hline $\mathrm{dn} i \mathrm{e}(1,1)$ & $\operatorname{dn} e(2,1)$ & dnie $(3,1)$ & $\operatorname{dn} e(4,1)$ & $\mathrm{dn} e(5,1)$ & $\operatorname{dn} e(6,1)$ & & \\
\hline phc & the & pmc & $\operatorname{tmc}$ & plc & tlc & tfinm & tfinh \\
\hline $\operatorname{dn} \mathrm{ie}^{\mathrm{e}}\left(7, \mathrm{k}_{\mathrm{i}}\right)$ & $\mathrm{dn}: e(8, \mathrm{k})$ & $\operatorname{dnlie}(9, \mathrm{ki})$ & $\operatorname{dnie}\left(10, \mathrm{k}_{\mathrm{i}}\right.$ & $\mathrm{dn}_{\mathrm{i}} \mathrm{e}\left(11, \mathrm{k}_{\mathrm{i}}\right)$ & j) $d n_{i}\left(12, k_{i}\right)$ & $\mathrm{dn} \mathrm{n}_{\mathrm{i}}\left(\mathrm{k}_{\mathrm{i}}\right)$ & $\operatorname{dn} e_{i}\left(k_{j}\right)$ \\
\hline
\end{tabular}

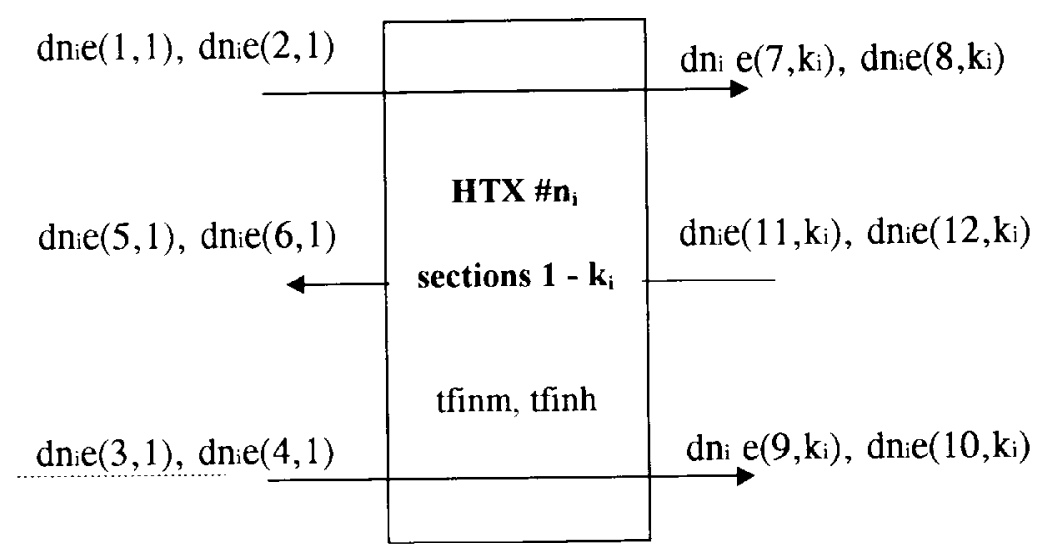

The following array represents all geometrical, heat loss and flow parameters for a 3-path heat exchanger, where $n_{i}=4,5,6$ :

\begin{tabular}{|c|c|c|c|c|c|c|c|c|}
\hline awh & awm & awl & ach & acm & acl & flen & qloss & fh \\
\hline $\operatorname{dn} x(1)$ & $\operatorname{dn} x(2)$ & $\operatorname{dn} x(3)$ & $\operatorname{dn} x(4)$ & $\operatorname{dn} x(5)$ & $\operatorname{dn} x(6)$ & $\operatorname{dn} x(7)$ & $\operatorname{dn} x(8)$ & $\operatorname{dn} \times(9)$ \\
\hline
\end{tabular}


\begin{tabular}{c|c|}
$\mathrm{fm}$ & $\mathrm{fl}$ \\
\hline $\mathrm{dn} \mathrm{x}(10)$ & $\mathrm{dn} \mathrm{x}(11)$ \\
\hline
\end{tabular}

The following parameters are defined as inputs and can be read from an external file for every run of the model:

- $\quad f h=\operatorname{dn}_{2} x(1)$, high path flow

- $\quad \mathrm{sp} 1=\mathrm{f} 1 / \mathrm{fh}$, ratio of turbine 1 flow to the coldbox flow

- $\operatorname{sp} 2=\mathrm{f} 2 / \mathrm{f} 1$, ratio of turbine 2 flow to turbine 1 flow

- $\operatorname{sp} 3=$ fwe/(1-sp 1$)$, ratio of wet engine flow to coldbox high side flow

- $\quad$ phw $=\mathrm{d} 2 \mathrm{e}(1,1)$, thw $=\mathrm{d} 2 \mathrm{e}(2,1)$, parameters of the high path warm end

- $p m w=d 4 e(3,1)$, midline pressure

- $\quad \mathrm{plw}=\mathrm{d} 2 \mathrm{e}(3,1)$, pressure of the coldbox low path warm end (compressor suction)

- pring, pressure of the subcooler tube-side flow to the Ring (demand pressure)

- tlow, temperature of the subcooler tube-side flow to the Ring (demand temperature)

- effwe, efficiency of wet engine

\section{STRUCTURE OF THE FORTRAN CODE}

The model uses the geometry of each heat exchanger to calculate the heat transfer at each point in the heat exchanger, unlike the programs which use an overall transfer coefficient UA and a $\log$ mean temperature difference formulation. This is why it is necessary to go to a relaxation method, because the number of unknowns and equations becomes two times the number of steps or elements, typically 50 to 500 . The intention of the authors was to make a program that uses the high pass temperature at the warm end and the low pass temperature at the cold end as inputs. That generates a logical and stable calculation to use the incoming flow parameters as inputs. Experience has shown that using outgoing flow parameters as inputs is prone to experience unphysical inputs that the system can not attain.

Each element is stored and solved, using the above parameters as input parameters. Afterwards, each and all the elements are relaxed by replacing pressure and temperature from above for the high and middle paths, and pressure and temperature from below for the low path. Similarly, the same approach is used for the whole heat exchangers train by propagating calculation results as inputs for next heat exchangers after each step of iteration. For instance, for section $\mathrm{k}_{\mathrm{i}}=32$ of the heat exchanger $n_{i}=3$ : phw $(32)=\mathrm{d} 3 \mathrm{e}(1,32)$ is replaced with $\operatorname{phc}(31)=\mathrm{d} 3 \mathrm{e}(5,31) ; \operatorname{tlc}(32)=\mathrm{d} 3 \mathrm{e}(8,32)$ is replaced with $\operatorname{tlw}(33)=\mathrm{d} 3 \mathrm{e}(4,33)$; etc.

The model reads in eight data files, one for each heat exchanger with geometrical data and guess values of process parameters for each section, plus a data file for the rest of the input data discussed above. The guess values for the each section process parameters are generated with a separate FORTRAN code based on the known heat exchanger experimental/design global process data, number of sections, and linear distribution. The structure of the input data files is identical to the structure of the output data files of the code. This allows for a sequential iteration when an output data files can be easily copied into an input data files needed later.

The following equations and external subroutines serve to link the process parameters ${ }^{1}$ :

\footnotetext{
${ }^{1}$ Subroutines SHAUG, DFPT, TFDP, etc. are external subroutines from HEPAK FORTRAN code.
} 
- the turbines' input parameters:

$$
\begin{array}{ll}
\mathrm{p} 11=\mathrm{d} 2 \mathrm{e}(5, \mathrm{n} 2) & \text { - turbine } 1 \text { inlet pressure } \\
\mathrm{p} 21=\mathrm{d} 4 \mathrm{e}(3,1) & \text { - turbine } 1 \text { exit pressure } \\
\mathrm{t} 11=\mathrm{d} 2 \mathrm{e}(6, \mathrm{n} 2) & \text { - turbine } 1 \text { inlet temperature } \\
\mathrm{p} 12=\mathrm{d} 4 \mathrm{e}(9, \mathrm{n} 4) & \text { - turbine } 2 \text { inlet pressure } \\
\mathrm{p} 22=\mathrm{d} 5 \mathrm{e}(11, \mathrm{n} 5) & \text { - turbine } 2 \text { exit pressure } \\
\mathrm{t} 12=\mathrm{d} 4 \mathrm{e}(10, \mathrm{n} 4) & \text { - turbine } 2 \text { inlet temperature } \\
\mathrm{p} 13=\mathrm{d} 6 \mathrm{e}(9, \mathrm{n} 6) & \text { - turbine } 3 \text { inlet pressure } \\
\mathrm{p} 23=\mathrm{d} 7 \mathrm{e}(7, \mathrm{n} 7) & \text { - turbine } 3 \text { exit pressure } \\
\mathrm{t} 13=\mathrm{d} 6 \mathrm{e}(10, \mathrm{n} 6) & \text { - turbine } 3 \text { inlet temperature } \\
\mathrm{f} 1=\mathrm{d} 2 \mathrm{x}(7) * \mathrm{sp} 1 & \text { - turbine } 1 \text { flow } \\
\mathrm{f} 2=\mathrm{f} 1 * \operatorname{sp} 2 & \text { - turbine } 2 \text { flow } \\
\mathrm{f} 3=\mathrm{fl} 1^{*}(1-\mathrm{sp} 2) & \text { - turbine } 3 \text { flow }
\end{array}
$$

- turbines' output properties are calculated in special subroutines:

CALL TURB1(p11,p21,t11,f1,eff 1,t21,dh1,speed 1) - calculates properties for turbine 1

CALL TURB2(p12,p22,t12,f2,eff2,t22, dh2,speed2) - calculates properties for turbine 2

CALL TURB3(p13,p23,t13,f3,eff3,t23,dh3,speed3) - calculates properties for turbine 3

- heat exchangers' output properties are calculated in special subroutines X2 and X3:

CALL X2(d2x,d2e,d2ef,n2,2)

CALL X2(d3x,d3e,d3ef,n3,3)

CALL X3(d4x,d4e,d4eh,d4em,n4,4)

CALL X3(d5x,d5e,d5eh,d5em,n5,5)

CALL X3(d6x,d6e,d6eh,d6em,n6,6)

CALL X2(d7x,d7e,d7ef,n7,7)

CALL X2(d8x,d8e,d8ef,n8,8)
- calculate properties for HTX2

- calculate properties for HTX3

- calculate properties for HTX4

- calculate properties for HTX5

- calculate properties for HTX6

- calculate properties for HTX7

- calculate properties for HTX8

- return flow fl is calculated by propagating from HTX \#8 through JT and WE, combining these two flows in the MIX3, and finally calculating the split 4 and return flow fl. First we start with wet engine and JT flows:

$$
\begin{array}{ll}
\text { fwe }=f h *(1 .-s p 1) * \operatorname{sp} 3 & \text { - wet engine flow } \\
\text { fjt }=f h *(1 .-s p 1) *(1 .-s p 3) & \text { - JT flow }
\end{array}
$$

- then we calculate the JT and wet engine exit conditions:

CALL JT(d8e(5,n8), d8e(6,n8),pring,tjt,q)

- isenthalpic expansion in JT valve for given inlet conditions, and exit pressure

CALL ENG(d8e(5,n8), d8e(6,n8),pring,twe,hwe,effwe) - expansion with given efficiency, given inlet conditions, and exit pressure 
- subcooler inlet parameters are calculated in special subroutine MIX. This subroutine reads the parameters of two incoming flows, and calculates the enthalpy and temperature of the mix at a given pressure:

CALL MIX(pring,twe, fwe,tjt, fjt,tsub,f) - calculate subcooler inlet properties

- then we calculate the split between flow to the Ring and subcooler flow, which is necessary to maintain the coldbox return temperature tlow at a given level. Here we define flow ' $f$ ' as a total flow from $\operatorname{HTX} 8=d 8 \times(7)$, flow 'fl' as a coldbox return flow, and calculate $\mathrm{sp} 4=\mathrm{fl} / \mathrm{f}$ :

CALL SUBC(tlow,pring,tsub,f,d8e(7,n8),sp4)

- calculate the subcooler shell side flow

- then the Ring and coldbox return flows:

$$
\begin{aligned}
& \mathrm{fsc}=\mathrm{fh} *(1 .-\mathrm{sp} 1) * \operatorname{sp} 4 \\
& \text { fring }=\mathrm{fh} *(1 .-\mathrm{sp} 1) *(1 .-\mathrm{sp} 4) \\
& \mathrm{fl}=\mathrm{fsc}
\end{aligned}
$$

- flow to the shell side of the subcooler

- flow to the Ring via the tube side of the subcooler

- return flow to the low path of the coldbox

- then the heat exchangers low path flows:

$$
\begin{aligned}
& \mathrm{d} 8 \mathrm{x}(8)=\mathrm{fl} \\
& \mathrm{d} 7 \mathrm{x}(8)=\mathrm{fl}+\mathrm{f} 3 \\
& \mathrm{~d} 6 \mathrm{x}(11)=\mathrm{fl}+\mathrm{f} 3 \\
& \mathrm{~d} 5 \mathrm{x}(11)=\mathrm{fl}+\mathrm{f} 3+\mathrm{f} 2 \\
& \mathrm{~d} 4 \mathrm{x}(11)=\mathrm{fl}+\mathrm{f} 3+\mathrm{f} 2 \\
& \mathrm{~d} 3 \mathrm{x}(8)=\mathrm{fl}+\mathrm{f} 3+\mathrm{f} 2 \\
& \mathrm{~d} 2 \mathrm{x}(8)=\mathrm{fl}+\mathrm{f} 3+\mathrm{f} 2
\end{aligned}
$$

- flow through HTX8 low path

- flow through HTX7 low path

- flow through HTX6 low path

- flow through HTX5 low path

- flow through HTX4 low path

- flow through HTX3 low path

- flow through HTX2 low path

- heat exchangers middle path flows:

$$
\begin{aligned}
& \mathrm{d} 4 \mathrm{x}(10)=\mathrm{f} 1 \\
& \mathrm{~d} 5 \mathrm{x}(10)=\mathrm{f} 3 \\
& \mathrm{~d} 6 \mathrm{x}(10)=\mathrm{f} 3
\end{aligned}
$$

- flow through HTX4 mid path

- flow through HTX5 mid path

- flow through HTX6 mid path

- then we update for the first time the input parameters:

$$
\begin{aligned}
& \mathrm{d} 2 \mathrm{e}(1,1)=\text { phw } \\
& \mathrm{d} 2 \mathrm{e}(2,1)=\text { thw } \\
& \mathrm{d} 4 \mathrm{e}(3,1)=\mathrm{pmw} \\
& \mathrm{d} 8 \mathrm{e}(8, \mathrm{n} 8)=\text { tlow } \\
& \mathrm{d} 2 \mathrm{e}(3,1)=\mathrm{plw} \\
& \mathrm{d} 2 \mathrm{x}(7)=\mathrm{fh} \\
& \mathrm{d} 3 \mathrm{x}(7)=\mathrm{fh} *(1-\mathrm{sp} 1) \\
& \mathrm{d} 4 \mathrm{x}(9)=\mathrm{fh} *(1-\mathrm{sp} 1) \\
& \mathrm{d} 5 \mathrm{x}(9)=\mathrm{fh} *(1-\mathrm{sp} 1) \\
& \mathrm{d} 6 \mathrm{x}(9)=\mathrm{fh} *(1-\mathrm{sp} 1) \\
& \mathrm{d} 7 \mathrm{x}(7)=\mathrm{fh} *(1-\mathrm{sp} 1)
\end{aligned}
$$

- HTX2 high path inlet pressure

- HTX2 high path inlet temperature

- HTX4 mid path inlet pressure

- HTX8 low path inlet temperature

- HTX2 low path exit pressure

- HTX2 high path flow

- HTX2 high path flow

- HTX2 high path flow

- HTX2 high path flow

- HTX2 high path flow

- HTX2 high path flow 
$\mathrm{d} 8 \mathrm{x}(7)=\mathrm{fh} *(1-\mathrm{sp} 1)$

$\mathrm{d} 4 \mathrm{e}(4,1)=\mathrm{t} 21$
- HTX2 high path flow

- HTX4 mid path warm end = turbine 1 exit temperature

- HTX5 and HTX7 low path cold end temperatures are calculated with a special subroutine MIX. This subroutine reads the parameters of two incoming flows, and calculates the enthalpy and temperature of the mix at a given pressure:

CALL MIX(d5e(11,n5),t22,f2,d6e(6,1),d6x(11),d5e(12,n5),d5x(11)) - for HTX5

CALL MIX(d7e(7,n7),t23,f3,d8e(4,1),d8x(8),d7e(8,n7),d7x(8)) - for HTX7

Additionally, we can now complete lacing for the heat exchangers pressures and temperatures. This lacing propagates from heat cxchanger $\# 2$ to heat exchanger $\# 8$ in the high path, from heat exchanger $\# 4$ to heat exchanger \#6 in the midlle path, and from heat exchanger $\# 8$ to heat exchanger \#2 in the low path. For low path the compressor suction pressure plw is fixed, thus lacing for pressures propagates from heat exchanger $\# 2$ to heat exchanger $\# 8$, opposite the direction of the helium flow.

$\begin{array}{ll}\text { from HTX \#2 to \#3: } & \text { from HTX \#3 to \#4: } \\ \text { d3e }(1,1)=\mathrm{d} 2 \mathrm{e}(5, \mathrm{n} 2) & \mathrm{d} 4 \mathrm{e}(1,1)=\mathrm{d} 3 \mathrm{e}(5, \mathrm{n} 3) \\ \mathrm{d} 3 \mathrm{e}(2,1)=\mathrm{d} 2 \mathrm{e}(6, \mathrm{n} 2) & \mathrm{d} 4 \mathrm{e}(2,1)=\mathrm{d} 3 \mathrm{e}(6, \mathrm{n} 3) \\ \mathrm{d} 3 \mathrm{e}(3,1)=\mathrm{d} 2 \mathrm{e}(7, \mathrm{n} 2) & \mathrm{d} 4 \mathrm{e}(5,1)=\mathrm{d} 3 \mathrm{e}(7, \mathrm{n} 3) \\ \mathrm{d} 2 \mathrm{e}(8, \mathrm{n} 2)=\mathrm{d} 3 \mathrm{e}(4,1) & \mathrm{d} 3 \mathrm{e}(8, \mathrm{n} 3)=\mathrm{d} 4 \mathrm{e}(6,1) \\ & \\ \text { from HTX \#4 to \#5: } & \text { from HTX \#5 to \#6: } \\ \text { d5e }(1,1)=\mathrm{d} 4 \mathrm{e}(7, \mathrm{n} 4) & \mathrm{d} 6 \mathrm{e}(1,1)=\mathrm{d} 5 \mathrm{e}(7, \mathrm{n} 5) \\ \mathrm{d} 5 \mathrm{e}(2,1)=\mathrm{d} 4 \mathrm{e}(8, \mathrm{n} 4) & \mathrm{d} 6 \mathrm{e}(2,1)=\mathrm{d} 5 \mathrm{e}(8, \mathrm{n} 5) \\ \mathrm{d} 5 \mathrm{e}(5,1)=\mathrm{d} 4 \mathrm{e}(11, \mathrm{n} 4) & \mathrm{d} 6 \mathrm{e}(5,1)=\mathrm{d} 5 \mathrm{e}(11, \mathrm{n} 5) \\ \mathrm{d} 4 \mathrm{e}(12, \mathrm{n} 4)=\mathrm{d} 5 \mathrm{e}(6,1) & \mathrm{d} 5 \mathrm{e}(12, \mathrm{n} 5)=\mathrm{already} \text { defined in MIX1 } \\ \text { d5e }(3,1)=\mathrm{d} 4 \mathrm{e}(9, \mathrm{n} 4) & \mathrm{d} 6 \mathrm{e}(3,1)=\mathrm{d} 5 \mathrm{e}(9, \mathrm{n} 5) \\ \mathrm{d} 5 \mathrm{e}(4,1)=\mathrm{d} 4 \mathrm{e}(10, \mathrm{n} 4) & \mathrm{d} 6 \mathrm{e}(4,1)=\mathrm{d} 5 \mathrm{e}(10, \mathrm{n} 5) \\ & \\ \text { from HTX \#6 to \#7: } & \text { from HTX \#7 to \#8: } \\ \text { d7e }(1,1)=\mathrm{d} 6 \mathrm{e}(7, \mathrm{n} 6) & \mathrm{d} 8 \mathrm{e}(1,1)=\mathrm{d} 7 \mathrm{e}(5, \mathrm{n} 7) \\ \mathrm{d} 7 \mathrm{e}(2,1)=\mathrm{d} 6 \mathrm{e}(8, \mathrm{n} 6) & \mathrm{d} 8 \mathrm{e}(2,1)=\mathrm{d} 7 \mathrm{e}(6, \mathrm{n} 7) \\ \mathrm{d} 7 \mathrm{e}(3,1)=\mathrm{d} 6 \mathrm{e}(11, \mathrm{n} 6) & \mathrm{d} 8 \mathrm{e}(3,1)=\mathrm{d} 7 \mathrm{e}(7, \mathrm{n} 7) \\ \text { d6e }(12, \mathrm{n} 6)=\mathrm{d} 7 \mathrm{e}(4,1) & \mathrm{d} 7 \mathrm{e}(8, \mathrm{n} 7)=\mathrm{already} \text { defined in MIX2 }\end{array}$

By this time all lacing between the heat exchangers is completed. Then we make series of checks or counting to decide whether the coldbox equations have already converged or not. Additionally we calculate the heat balance for the complete coldbox. Ballance is:

$$
B=f h \cdot h h w-f r i n g \cdot h r i n g-f l \cdot h l w+\sum_{i=2}^{8} \text { radiation }_{i}-\sum_{i=1}^{3} f_{i} \cdot \Delta \text { hturbine }_{i}
$$

where: hhw=coldbox HTX2 high path inlet enthalpy; hring=enthalpy of the ring flow; hlw=entalpy of the return flow; $\Delta$ hturbine $_{\mathrm{i}}=$ enthalpy drop in turbine . $_{\text {. }}$

\section{DESCRIPTION OF SUBROUTINES FOR COLDBOX ELEMENTS}

A) Subroutines X2 and X3. These subroutines are for 2-path and 3-path heat exchangers respectively. They use an internal loop to find the solution for parameters at the low path warm end and high path 
cold end for each section of the heat exchanger. Subroutine X3 additionally finds the solution for parameters at the middle path cold end for each section of the 3-path heat exchanger. These solutions are used to update array of parameters dnie. Each 2-path or 3-path heat exchanger has a unique geometrical data and unique number of sections, thus the subroutine X2 or X3 is called respectively for each heat exchanger with unique array of geometrical data dnix. Note that the defining inputs at the warm end of the high path and the middle path do not need to be the same. Furthermore, the cold end parameters do not in general come out to be the same for the high path and the middle path. The authors do not know of any other calculations of 3-path heat exchanger which provides for this generality. To calculate temperatures of the fins X2 and X3 call in the external subroutine HEAT in each step of iteration. The heat transfer for each element is calculated via enthalpy change. External heat loss qloss is assumed as distributed equally through all sections of a given heat exchanger. After new process parameters have been calculated for each section, the sections are laced together so that the input corners influence can propagate through the heat exchanger toward the output end. Below is an example of subroutine $\mathrm{X} 3$ :

SUBROUTINE x3(d4x,d4e,d4eh,d4em,n,kkk) IMPLICIT DOUBLE PRECISION (A-H,O-Z) DIMENSION d4e(12,n), d4x(11), d4eh(n),d4em(n) here: $\mathrm{n}$ - number of sections; kkk - an index indicating the type of the heat exchanger to select the right curves for heat transfer and $\Delta \mathrm{p}$ coefficients.

$$
\begin{aligned}
& \mathrm{fh}=\mathrm{d} 4 \mathrm{x}(9) \\
& \mathrm{fm}=\mathrm{d} 4 \mathrm{x}(10) \\
& \mathrm{fl}=\mathrm{d} 4 \mathrm{x}(11)
\end{aligned}
$$

- defining the high path flow

- defining the mid path flow

- defining the low path flow

We begin the element loop, find a solution for lw and hc, mc variables for each element and stuff it in the array dnie to update this array. First the geometry calculations:

$$
\begin{aligned}
& \text { awh }=\mathrm{d} 4 \mathrm{x}(1) \\
& \mathrm{awm}=\mathrm{d} 4 \mathrm{x}(2) \\
& \mathrm{awl}=\mathrm{d} 4 \mathrm{x}(3) \\
& \mathrm{ach}=\mathrm{d} 4 \mathrm{x}(4) \\
& \mathrm{acm}=\mathrm{d} 4 \mathrm{x}(5) \\
& \mathrm{acl}=\mathrm{d} 4 \mathrm{x}(6) \\
& \text { flen }=\mathrm{d} 4 \mathrm{x}(7) \\
& \text { deh }=4 .^{*}(\mathrm{ach} * \text { flen/awh }) \\
& \text { dem }=4 .^{*}(\mathrm{acm} * \text { flen/awm }) \\
& \text { del }=4 . *(\mathrm{acl} * \text { flen/awl }) \\
& \text { step }=\mathrm{n} \\
& \mathrm{dx}=\text { flen/step } \\
& \text { qloss }=\mathrm{d} 4 \mathrm{x}(8)
\end{aligned}
$$

- wetted fin area for high path

- wetted fin area for mid path

- wetted fin area for low path

- flow cross section area for high path

- flow cross section area for mid path

- flow cross section area for low path

- effective length of the heat exchanger

- hydraulic diameter for the high path

- hydraulic diameter for the mid path

- hydraulic diameter for the low path

- number of sections in the heat exchanger

- length of one section

- radiation loss

Then each element is solved separately within an outer loop:

DO $99 \mathrm{i}=1, \mathrm{n}$
phw $=\mathrm{d} 4 \mathrm{e}(1, \mathrm{i})$
thw $=\mathrm{d} 4 \mathrm{e}(2, \mathrm{i})$
$\mathrm{pmw}=\mathrm{d} 4 \mathrm{e}(3, \mathrm{i})$
$\mathrm{tmw}=\mathrm{d} 4 \mathrm{e}(4, \mathrm{i})$
plw $=\mathrm{d} 4 \mathrm{e}(5, \mathrm{i})$
$\mathrm{tl} \mathrm{w}=\mathrm{d} 4 \mathrm{e}(6, \mathrm{i})$
$\mathrm{phc}=\mathrm{d} 4 \mathrm{e}(7, \mathrm{i})$
$\mathrm{pmc}=\mathrm{d} 4 \mathrm{e}(9, \mathrm{i})$
thc $=\mathrm{d} 4 \mathrm{e}(8, \mathrm{i})$ 

$\mathrm{tmc}=\mathrm{d} 4 \mathrm{e}(10, \mathrm{i})$
$\mathrm{tlc}=\mathrm{d} 4 \mathrm{e}(12, \mathrm{i})$
tfinm $=\mathrm{d} 4 \mathrm{em}(\mathrm{i})$
$\mathrm{plc}=\mathrm{d} 4 \mathrm{e}(11, \mathrm{i})$
tfinh $=\mathrm{d} 4 \mathrm{eh}(\mathrm{i})$

Then we begin the element loop, converge each element based on stability in tlw, thc, tmc. Later we decided to remove the loop to speed up calculations without decreasing the stability.

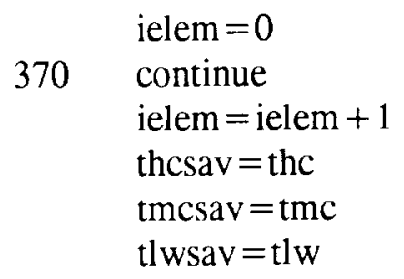

At this point we begin the inner loop, fin loop. Its function is to iterate tfinx until they converge.

$\begin{array}{ll}386 & \text { ifin }=0 \\ \text { continue }\end{array}$
ifin $=$ ifin +1
th $=($ thw + thc $) / 2$.
$\mathrm{pm}=(\mathrm{pmw}+\mathrm{pmc}) / 2$
savh $=$ tfinh
$\mathrm{ph}=(\mathrm{phw}+\mathrm{phc}) / 2$.
$\mathrm{tl}=(\mathrm{tlw}+\mathrm{tlc}) / 2$.
savm $=$ tfinm
$\mathrm{tm}=(\mathrm{tmw}+\mathrm{tmc}) / 2$.
$\mathrm{pl}=(\mathrm{plw}+\mathrm{plc}) / 2$.

We use indexes for: index $=1$ for high path, $=2$ for low path, and $=3$ for middle path:

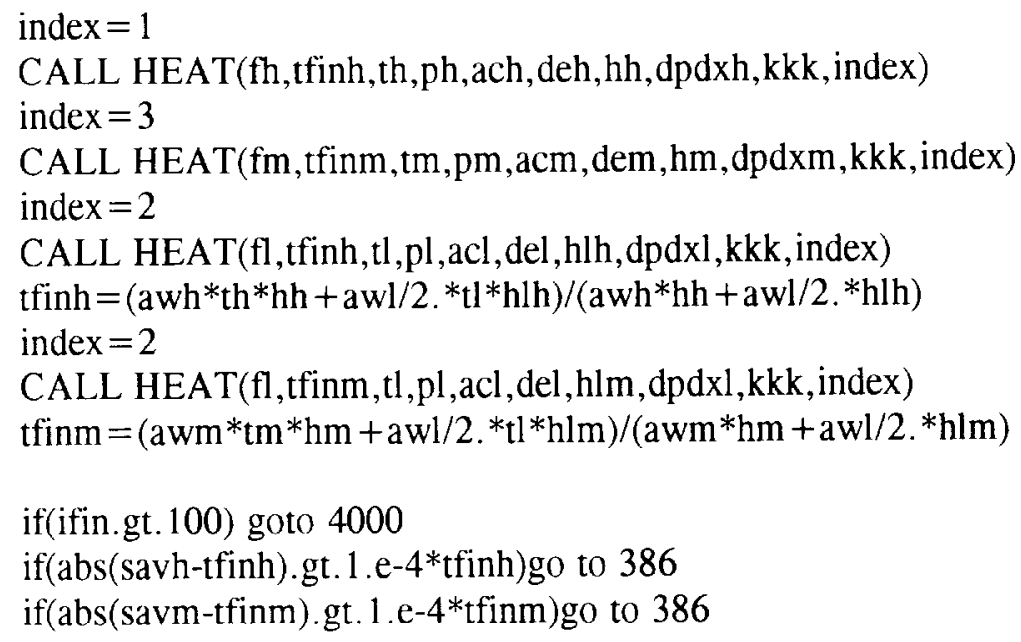

This is the end of the fin loop.

4000 continue

$$
\begin{aligned}
& d p l=d p d x l^{*} d x \\
& d p h=d p d x h^{* d x} \\
& d p m=d p d x m^{*} d x
\end{aligned}
$$

$$
\begin{aligned}
& \mathrm{qh}=\mathrm{awh} * \mathrm{hh} *(\mathrm{th}-\mathrm{tfinh}) / \mathrm{step} \\
& \mathrm{qm}=\mathrm{awm} * \mathrm{hm} *(\mathrm{tm}-\mathrm{tfinm}) / \mathrm{step}
\end{aligned}
$$

Then we calculate the heat transferred into cach element and update the element. Subroutine DFPT finds density from given pressure and temperature. Subroutine SHAUG finds entropy and enthalpy 
from given density, pressure, and temperature. Subroutine DTFPX finds density and temperature from given pressure and enthalpy.

CALL DFPT(ID, dhw,Q,phw,thw)

CALL SHAUG(S,ehw, A,U, G,phw,dhw,thw)

CALL DFPT(ID,dmw,Q,pmw,tmw)

CALL SHAUG(S,emw,A,U,G,pmw,dmw,tmw)

phc $=$ phw-dph

ehc $=$ ehw-qh/fh

CALL DTFPX(ID, dhc,thc,Q,DL,DV,DPDDDTS,phc,ehc, 'PH')

$\mathrm{pmc}=\mathrm{pmw}-\mathrm{dpm}$

$\mathrm{emc}=\mathrm{emw}-\mathrm{qm} / \mathrm{fm}$

CALL DTFPX(ID,dmc,tmc,Q,DL,DV,DPDDDTS,pmc,emc, 'PH')

$\mathrm{plc}=\mathrm{plw}+\mathrm{dpl}$

CALL DFPT(ID, dlc,Q,plc,tlc)

CALL SHAUG(S,elc,A,U,G,plc, dlc,tlc)

$\mathrm{elw}=\mathrm{elc}+(\mathrm{qh}+\mathrm{qm}+\mathrm{qloss} / \mathrm{step}) / \mathrm{fl}$

CALL DTFPX(ID,dlw,tlw,Q,DL, DV,DPDDDTS,plw,elw, 'PH')

By this point the output parameters have been computed from the input corners. The next step is to load the results into the process array dnie and fin arrays dniem and dnieh.

if(ielem.gt. 100) goto 5000

if(abs(thcsav-thc).gt. 1.e-4*thc)go to 370

if(abs(tmcsav-tmc).gt. 1.e-4*tmc)go to 370

if(abs(tlwsav-tlw).gt.1.e-4*tlw)go to 370

5000 continue
$\mathrm{d} 4 \mathrm{e}(11, \mathrm{i})=\mathrm{plc}$
$\mathrm{d} 4 \mathrm{e}(9, \mathrm{i})=\mathrm{pmc}$
$\mathrm{d} 4 \mathrm{e}(8, \mathrm{i})=$ thc
$\mathrm{d} 4 \mathrm{eh}(\mathrm{i})=\mathrm{tfinh}$
$\mathrm{d} 4 \mathrm{e}(6, \mathrm{i})=\mathrm{tlw}$
$\mathrm{d} 4 \mathrm{e}(10, \mathrm{i})=\mathrm{tmc}$
d4em $(i)=$ tfinm

99 continue

DO $197 \mathrm{i}=1, \mathrm{n}-1$

$$
\begin{aligned}
& d 4 e(5, i+1)=d 4 e(11, i) \\
& d 4 e(12, i)=d 4 e(6, i+1) \\
& d 4 e(1, i+1)=d 4 e(7, i)
\end{aligned}
$$

$$
\begin{aligned}
& \mathrm{d} 4 \mathrm{e}(3, \mathrm{i}+1)=\mathrm{d} 4 \mathrm{e}(9, \mathrm{i}) \\
& \mathrm{d} 4 \mathrm{e}(2, \mathrm{i}+1)=\mathrm{d} 4 \mathrm{e}(8, \mathrm{i}) \\
& \mathrm{d} 4 \mathrm{e}(4, \mathrm{i}+1)=\mathrm{d} 4 \mathrm{e}(10, \mathrm{i})
\end{aligned}
$$

197 continue

RETURN

END

B) Subroutine HEAT. This subroutine calculates heat transfer coefficient hh and pressure drop coefficient $d p d x$ for a given set of process parameters and geometrical data of a single section of a plate-fin heat exchanger. The subroutine uses the same equations and coefficients for every section of a given heat exchanger, but unique equations and coefficients for each of the coldbox heat exchanger. This subroutine needs Reynolds and Prandtl numbers, which are calculated based on mass flow and 
mean temperature between fins and bulk fluid. Density, viscosity, thermal conductivity, and heat capacity at constant pressure calculations are done using HEPAK external subroutines.

SUBROUTINE HEAT(fh,tfin,th,ph,ach, deh, hh, dpdx, kkk, index)

IMPLICIT DOUBLE PRECISION (A-H,O-Z)

$f m d o t=f h \quad-$ note that the label ' $h$ ' for the high pass is used in the argument list, though the calling argument list will reflect the correct pass.

$\mathrm{g}=\mathrm{fmdot} / \mathrm{ach} \quad-$ mass flow rate per unit area

tempm $=0.5^{*}(\mathrm{tfin}+\mathrm{th})-$ ' $\mathrm{m}$ ' is used for mean temperature between wall and bulk fluid which should be used to calculate properties.

CALL DFPT(id,densm,q,ph,tempm) - gives the density at the mean temperature

CALL DFPT(id,densb, q,ph,th) - gives the density at the bulk temperature

$\mathrm{fmu}=\mathrm{viscos}(\mathrm{densm}, \mathrm{tempm})$

- absolute viscosity at mean temperature, $\mathrm{Pa} / \mathrm{s}$

fmub $=v i s \cos ($ densb, th $)$

$\operatorname{Re}=\mathrm{deh}^{*} \mathrm{~g} / \mathrm{fmu}$

- absolute viscosity at bulk temperature, $\mathrm{Pa} / \mathrm{s}$

cpp $=c p($ densm,tempm $)$

- Rcynolds number

tcond $=$ tcon(densm,tempm)

- heat capacity at mean temperature

$\operatorname{Pr}=\mathrm{cpp} * \mathrm{fmu} / \mathrm{tcond}$

- thermal conductivity of gas at mean temperature

- Prandlt number

The following logical statements define the selection of the specific curve for heat transfer and $\Delta \mathrm{p}$ coefficients:

if(kkk.eq.2.and.index.eq.1) goto 100 - HTX2 high path

if(kkk.eq.2.and.index.eq.2) goto 101 - HTX2 low path

if(kkk.eq.3.and.index.eq.1) goto 100 - HTX3 high path

if(kkk.eq.7.and.index.eq.2) goto 101 - HTX7 low path

if(kkk.eq.7.and.index.eq.1) goto 102 - HTX8 high path

if(kkk.eq.6.and.index.eq.3) goto 100 - HTX8 low path

$100 \mathrm{dpdx}=$ Function $(\text { Re, densm, deh, } \mathrm{g})^{2}$

$\mathrm{hh}=$ Function $(\mathrm{Re}, \mathrm{Pr}, \mathrm{cpp}, \mathrm{g})^{2}$

goto 103

$101 \mathrm{dndx}=$ Function $(\operatorname{Re}, \text { densm, deh, } \mathrm{g})^{2}$

$\mathrm{hh}=$ Function $(\mathrm{Re}, \mathrm{Pr}, \mathrm{cpp}, \mathrm{g})^{2}$

goto 103

$102 \mathrm{dpdx}=$ Function $(\text { Re, densm, deh, } \mathrm{g})^{2}$

$\mathrm{hh}=$ Function $(\mathrm{Re}, \mathrm{Pr}, \mathrm{cpp}, \mathrm{g})^{2}$

goto 103

103 continue

RETURN

END

\footnotetext{
${ }^{2}$ The coefricients of the equations are ALTEC International proprietary data
} 
C) Subroutines TURB1,2,3. These subroutines calculate efficiency of the respective expander as $\mathrm{dH} / \mathrm{dH}$ ideal based on the data provided by Rotoflow for $\mathrm{U} / \mathrm{C}$ and volumetric efficiencies. This subroutine calculate expander exit temperature based on inlet pressure, temperature, flow, and exit pressure. Below is an example of subroutine TURB1.

\section{SUBROUTINE TURB1(p1,p2,t1,fl,eff,t2,dh,speed) IMPLICIT DOUBLE PRECISION (A-H, O-Z)}

Notations and definitions: ' 1 ' $=$ inlet, $' 2$ ' $=$ exit parameters, ' $d$ ' $=$ design, ' $a$ ' $=$ actual. Input parameters are: $\mathrm{p} 1, \mathrm{p} 2, \mathrm{t} 1, \mathrm{fl}$. Output parameters are: eff, $\mathrm{t} 2, \mathrm{dh}=\mathrm{h} 1-\mathrm{h} 2$, speed. Additionally: $\mathrm{uc}=$ ratio of tip speed $\mathrm{U}$ over theoretical speed $\mathrm{C} 0$; dspeed=design speed; dvol=design volume flow; duc $=$ design $\mathrm{U} / \mathrm{C} 0$; deff $=$ design efficiency. At fist, we read eff and speed as iteration guess values. Then we define the design values:

$$
\begin{array}{lll}
\text { dspeed }=55000 . & \text { duc }=0.66 & \text { dflow }=1.2820 \\
\text { dvol }=0.1651847 & \text { deff }=0.82 & \text { ddh }=55451.274
\end{array}
$$

\begin{tabular}{|c|c|}
\hline $\begin{array}{l}\text { CALL DFPT(id,d1,q,p1,t1) } \\
\text { CALL SHAUG(s1,hl,a,u,g,pl,dl,t1) } \\
\text { s2=s1 } \\
\text { CALL DTFPX(id,d2,t2,q,dl,dv,dpdts,p2,s2,'PS') } \\
\text { CALL SHAUG(s2,h2i,a,u,g,p2,d2,t2) } \\
\text { dhi }=\text { h1-h2i } \\
\text { ac }=223.837 * \text { SQRT }\left(\mathrm{dhi}^{*} * 4.29927 \mathrm{e}-4\right)\end{array}$ & $\begin{array}{l}\text { - inlet density } \\
\text { - inlet entropy } \\
\text { - exit entropy } \\
\text { - exit density and temperature } \\
\text { - exit enthalpy h2i at ideal expansion } \\
\text { - ideal enthalpy change } \\
\text { - actual theoretical speed C }\end{array}$ \\
\hline
\end{tabular}

Then we compute the ideal expander, $d s=0$ :

$$
\mathrm{j}=0
$$

$6 \quad j=j+1$

$$
\begin{aligned}
& \text { aspeed }=\mathrm{dspeed}^{*}((\mathrm{fl} * \mathrm{dhi} * \mathrm{eff}) /(\mathrm{dflow} * \mathrm{ddh} * \mathrm{deff}))^{* *}(1 . / 2.8) \\
& \mathrm{au}=0.0130899^{*} \text { aspeed } \\
& \mathrm{auc}=\mathrm{au} / \mathrm{ac} \\
& \text { effu }=\text { Function }(\mathrm{auc})^{3} \\
& \text { h2 }=\text { h1-effu } *(\mathrm{~h} 1-\mathrm{h} 2 \mathrm{i}) \\
& \text { - actual exit enthalpy h2 } \\
& \text { CALL DTFPX (id,d2,t2,q,dl,dv,dpdts,p2,h2,'PH') - actual exit density and temperature } \\
& \mathrm{avol}=\mathrm{fl} / \mathrm{d} 2 \\
& \mathrm{xv}=\left(\text { avol }{ }^{*} \text { aspeed }\right) /(\mathrm{dvol} * \mathrm{dspeed}) \\
& \text { deffv }=\text { Function }(x v)^{3} \\
& \text { efft }=(\text { effu-deffv }) \\
& \text { - actual rpm } \\
& \text { - actual tip speed } \\
& \text { - actual U/C } \\
& \text { - actual effu } \\
& \text { aspeed }=\mathrm{dspeed} *((\mathrm{fl} * \mathrm{dhi} * \mathrm{efft}) /(\mathrm{dflow} * \mathrm{ddh} * \mathrm{deff})) * *(1 . / 2.8) \\
& \text { - volumetric flow, } \mathrm{m} 3 / \mathrm{sec} \\
& \text { - actual to design speed and flow ratio } \\
& \text { - drop in efficiency due to flow } \\
& \text { - 'total' efficiency from effu and deffv } \\
& \text { if(abs(efft-eff).le.1.e-5)go to } 5 \\
& \text { eff }=\text { efft }
\end{aligned}
$$

\footnotetext{
${ }^{3}$ Atlas Copco Rotoflow Corporation proprietary data
} 


$\begin{array}{ll} & \text { if(j.gt.20)go to } 5 \\ & \text { goto } 6 \\ & \text { eff }=\text { efft } \\ & \text { dh }=\text { h1-h2 } \\ & \text { speed }=\text { aspeed } \\ & \text { RETURN } \\ & \text { END }\end{array}$

the convergence condition is not satisfied

D) Subroutine SUBC. This subroutine adjusts the flow to the subcooler to maintain a given temperature (i.e. $4.7^{\circ} \mathrm{K}$ ) of the two phase helium routed back to the heat exchanger $\# 8$ on the low path, tlow. It is assumed that the subcooler is perfect and sends liquid helium to the Ring at the temperature tlow. Below is example of subroutine SUBC.

\section{SUBROUTINE SUBC(tlow,pring,tsub,f,plow,sp4) IMPLICIT DOUBLE PRECISION (a-h,o-z)}

Notations are: pring = pressure to the Ring, input data (assumption is that incoming pressure is pring, i.e. no pressure drop); tsub $=$ temperature coming in to the subcooler, input data; $f=$ cold flow coming out of the JT and WE, same as high side of heat exchanger \#8, same as coming into the subcooler, input data; flow = flow returning to HTX8, output data; plow = pressure at the low pressure cold end of heat exchanger $\# 8$, calculated data (from the total pressure drop in the coldbox low side); split $4=$ fractional flow to the subcooler, comes out as actual value. We assume that the throttling on the subcooler $J T$ is isenthalpic from pring to plow.

tsatv $=$ TSATFP(plow)

if (tlow.lt.tsatv) print 559

559 FORMAT(' Warning!!! 2 phase in HTX8!!!')

CALL DFPT(id,dsub, q,pring,tsub)

CALL SHAUG(ssub, hsub,a,u,g,pring,dsub,tsub)

CALL DFPT(id,dlow, q,plow, tlow)

CALL SHAUG(s, hlow,a,u,g,plow,dlow,tlow)

CALL DFPT(id,dring,q,pring,tlow)

CALL SHAUG(s, hring,a,u,g,pring, dring,tlow)
- saturation temperaure at plow

- check for liquid fraction

- warning message

- density of the tube side flow

- enthalpy of the tube side flow

- density of the shell side flow

- enthalpy of the shell side flow

- density of the flow to the Ring

- enthalpy of the flow to the Ring

Then the flow balance and heat balance give the solution for fl to the shell side of the subcooler:

$$
\begin{aligned}
& \mathrm{fl}=\mathrm{f} * \text { (hsub-hring }) /(\text { hlow-hring) } \\
& \mathrm{sp} 4=\mathrm{fl} / \mathrm{f} \\
& \text { RETURN } \\
& \text { END }
\end{aligned}
$$

E) Subroutines JT, MIX, and ENG calculate the exit properties respectively for: a) isenthalpic expansion in JT valve; b) mix of two mass flows with known parameters; c) expansion in expansion engine of known isentropic efficiency. These subroutines are straight-forward and use HEPAK cxtcrnal subroutines to calculate properties. 


\section{RESULTS OF THE SIMULATION}

As it was said earlier, the structure of the output data files generated by the model is identical to the structure of the input data files read into the code. The model generates eight data files, one for each heat exchanger with geometrical data and final values of process parameters for each section, plus a data file for the coldbox global input data. The typical coldbox global output data file generated by the code is shown below (all parameters in SI units).

\section{COLDBOX INPUT:}

\begin{tabular}{|l|l|l|l|l|l|l|l|l|l}
\hline sp1 & sp2 & sp3 & sp4 & effwe & imain & fh & thw & phw & pmw \\
\hline 0.7746 & 1.0000 & 0.7500 & 0.5000 & 0.3445 & 5000 & 1.400 & 82.000 & $0.13100 \mathrm{E}+07$ & $0.62050 \mathrm{E}+06$ \\
\hline
\end{tabular}

\begin{tabular}{|l|l|l|l}
\hline pring & tlow & plw \\
\hline $0.3309 \mathrm{E}+06$ & $0.1217 \mathrm{E}+06$ & 4.7 \\
\hline
\end{tabular}

\section{COLDBOX OUTPUT:}

\begin{tabular}{|c|c|c|c|c|c|}
\hline turb1 speed & turb2 speed & turb3 speed & turb1 eff & turb2 eff & turb3 eff \\
\hline 52429.75 & 49218.15 & 40276.52 & 0.7601 & 0.7314 & 0.7547 \\
\hline t 11 , turb 1 in & $\mathrm{t} 21$, turb 1 out & t12, turb2 in & $\mathrm{t} 22$, turb 2 out & t13, turb3 in & $\mathrm{t} 23$, turb 3 out \\
\hline 45.26 & 35.79 & 25.63 & 16.33 & 12.87 & 8.00 \\
\hline $\mathrm{fl}$ & $\mathrm{f} 2$ & $\mathrm{f} 3$ & fwe & fjt & fring \\
\hline 1.08437 & 0.54219 & 0.54219 & 0.31563 & 0.00000 & 0.20688 \\
\hline
\end{tabular}

HEAT EXCHANGERS OUTPUT DATA:

\begin{tabular}{|l|c|c|c|c|c|c|}
\hline $\begin{array}{l}\text { HTX\# } \\
\text { HTX\# }\end{array}$ & $\begin{array}{c}\text { phw } \\
\text { phc }\end{array}$ & $\begin{array}{c}\text { thw } \\
\text { thc }\end{array}$ & $\begin{array}{c}\text { plw } \\
\text { plc }\end{array}$ & $\begin{array}{c}\text { tlw } \\
\text { tlc }\end{array}$ & $\begin{array}{c}\text { pmw } \\
\text { pmc }\end{array}$ & $\begin{array}{c}\text { tmw } \\
\text { tmc }\end{array}$ \\
\hline 2 & $0.1900 \mathrm{E}+03$ & $0.8200 \mathrm{E}+02$ & $0.1766 \mathrm{E}+02$ & $0.8198 \mathrm{E}+02$ & & \\
\hline 2 & $0.1890 \mathrm{E}+03$ & $0.4526 \mathrm{E}+02$ & $0.1900 \mathrm{E}+02$ & $0.3835 \mathrm{E}+02$ & & \\
\hline 3 & $0.1890 \mathrm{E}+03$ & $0.4526 \mathrm{E}+02$ & $0.1900 \mathrm{E}+02$ & $0.3835 \mathrm{E}+02$ & & \\
\hline 3 & $0.1890 \mathrm{E}+03$ & $0.3762 \mathrm{E}+02$ & $0.1909 \mathrm{E}+02$ & $0.3625 \mathrm{E}+02$ & & \\
\hline 4 & $0.1890 \mathrm{E}+03$ & $0.3762 \mathrm{E}+02$ & $0.1909 \mathrm{E}+02$ & $0.3625 \mathrm{E}+02$ & $0.9000 \mathrm{E}+02$ & $0.3579 \mathrm{E}+02$ \\
\hline 5 & $0.1876 \mathrm{E}+03$ & $0.2363 \mathrm{E}+02$ & $0.1971 \mathrm{E}+02$ & $0.2291 \mathrm{E}+02$ & $0.8894 \mathrm{E}+02$ & $0.2563 \mathrm{E}+02$ \\
\hline 5 & $0.1876 \mathrm{E}+03$ & $0.2363 \mathrm{E}+02$ & $0.1971 \mathrm{E}+02$ & $0.2291 \mathrm{E}+02$ & $0.8894 \mathrm{E}+02$ & $0.2563 \mathrm{E}+02$ \\
\hline 6 & $0.1875 \mathrm{E}+03$ & $0.1634 \mathrm{E}+02$ & $0.2013 \mathrm{E}+02$ & $0.1633 \mathrm{E}+02$ & $0.8854 \mathrm{E}+02$ & $0.1634 \mathrm{E}+02$ \\
\hline 6 & $0.1875 \mathrm{E}+03$ & $0.1634 \mathrm{E}+02$ & $0.2013 \mathrm{E}+02$ & $0.1634 \mathrm{E}+02$ & $0.8854 \mathrm{E}+02$ & $0.1634 \mathrm{E}+02$ \\
\hline 7 & $0.1875 \mathrm{E}+03$ & $0.1292 \mathrm{E}+02$ & $0.2022 \mathrm{E}+02$ & $0.1115 \mathrm{E}+02$ & $0.8817 \mathrm{E}+02$ & $0.1287 \mathrm{E}+02$ \\
\hline 7 & $0.1875 \mathrm{E}+03$ & $0.1292 \mathrm{E}+02$ & $0.2022 \mathrm{E}+02$ & $0.1115 \mathrm{E}+02$ & & \\
\hline 8 & $0.1873 \mathrm{E}+03$ & $0.8002 \mathrm{E}+01$ & $0.2056 \mathrm{E}+02$ & $0.8002 \mathrm{E}+01$ & & \\
\hline
\end{tabular}

COLD BOX HEAT BALANCE $=-3.3223$ Watt $\quad$ tsub $=5.5135$

WORK DONE BY: T1, T2, T3 Watt $=54728.7281 \quad 25866.3529 \quad 11673.6043$

WORK DONE BY WE Watt $=1900.6436$ 
First, the simulation model has been checked upon several sets of experimentally known process conditions for 2-compressors and 3-compressors flows. The model has proven to be accurate within $5 \%$ when allowed to converge with sufficient number of iterations (normally greater than 7500 ). Then multiple runs have been performed to evaluate the coldbox liquid helium production to the Ring at different inlet conditions. The limiting factors of the present coldbox are: inlet pressure is less than 1.241 MPa, inlet flow is less than $1700 \mathrm{~g} / \mathrm{s}$, midline pressure is less than $0.62 \mathrm{MPa}$, and exit pressure is $\sim 0.331 \mathrm{MPa}$ psia. These limiting factors are reducing the overall potential increase of production resulting from JT valve replacement with an expander. The following table summarizes the results of simulation.

\begin{tabular}{|c|c|c|c|c|}
\hline Parameters: & \multicolumn{2}{|c|}{ 2-compressors flow } & \multicolumn{2}{|c|}{ 3-compressors flow } \\
\hline Coldbox inlet flow, kg/s & \multicolumn{2}{|c|}{1.143} & \multicolumn{2}{|c|}{1.601} \\
\hline Coldbox inlet pressure, $\mathrm{MPa}$ & \multicolumn{2}{|c|}{$1.1376(165$ psia $)$} & \multicolumn{2}{|c|}{$1.1376(165 \mathrm{psia}$} \\
\hline Coldbox inlet temp, ${ }^{\circ} \mathrm{K}$ & \multicolumn{2}{|c|}{80.0} & \multicolumn{2}{|c|}{80.0} \\
\hline Ring pressure, $\mathrm{MPa}$ & \multicolumn{2}{|c|}{0.331 (48 psia) } & \multicolumn{2}{|c|}{0.331 (48 psia) } \\
\hline Coldbox return temp, ${ }^{\circ} \mathrm{K}$ & \multicolumn{2}{|l|}{4.7} & \multicolumn{2}{|l|}{4.7} \\
\hline JT and WE split, \% & $100 \% \mathrm{JT}$ & $100 \% W E$ & $100 \% \mathrm{JT}$ & $100 \% W E$ \\
\hline Turbine 1 flow, $\mathrm{kg} / \mathrm{s}$ & 0.86265 & 0.89578 & 1.18907 & 1.24222 \\
\hline Turbine 2 flow, $\mathrm{kg} / \mathrm{s}$ & 0.43132 & 0.44789 & 0.59454 & 0.62111 \\
\hline Turbine 3 flow, $\mathrm{kg} / \mathrm{s}$ & 0.43132 & 0.44789 & 0.59454 & 0.62111 \\
\hline JT flow, $\mathrm{kg} / \mathrm{s}$ & 0.28035 & 0.00000 & 0.41192 & 0.00000 \\
\hline Expander flow, $\mathrm{kg} / \mathrm{s}$ & 0.00000 & 0.24722 & 0.00000 & 0.35878 \\
\hline Expander efficiency, $\%$ & 75.0 & 75.0 & 75.0 & 75.0 \\
\hline Expander work, Watt & 0.00000 & 1295.4873 & 0.00000 & 1832.7077 \\
\hline Turbine 1 speed, krpm & 43095 & 44762 & 51993 & 53339 \\
\hline Turbine 2 speed, krpm & 41785 & 43504 & 49849 & 51500 \\
\hline Turbine 3 speed, krpm & 34861 & 35941 & 40933 & 41747 \\
\hline Turbine 1 efficiency, $\%$ & 0.6392 & 0.6700 & 79.16 & 0.7991 \\
\hline Turbine 2 efficiency, $\%$ & 0.6088 & 0.6381 & 75.25 & 0.7719 \\
\hline Turbine 3 efficiency, $\%$ & 0.6481 & 0.6738 & 77.20 & 0.7790 \\
\hline Turbine 1 temp in, ${ }^{\circ} \mathrm{K}$ & 43.83 & 44.79 & 43.68 & 44.50 \\
\hline Turbine 1 temp out, ${ }^{\circ} \mathrm{K}$ & 36.12 & 36.78 & 35.43 & 36.09 \\
\hline Turbine 2 temp in, ${ }^{\circ} \mathrm{K}$ & 24.53 & 25.19 & 24.49 & 25.02 \\
\hline Turbine 2 temp out, ${ }^{\circ} \mathrm{K}$ & 16.20 & 16.51 & 15.81 & 16.13 \\
\hline Turbine 3 temp in, ${ }^{\circ} \mathrm{K}$ & 12.58 & 12.66 & 12.58 & 12.59 \\
\hline Turbine 3 temp out, ${ }^{\circ} \mathrm{K}$ & 8.00 & 8.0 & 8.00 & 8.00 \\
\hline Turbine 1 work, Watt & 35376 & 38156 & 52142 & 55546 \\
\hline Turbine 2 work, Watt & 18325 & 19902 & 26419 & 28310 \\
\hline Turbine 3 work, Watt & 8583 & 9125 & 12039 & 12620 \\
\hline Flow to JT and WE, $\mathrm{kg} / \mathrm{s}$ & 0.28035 & 0.24722 & 0.41192 & 0.35878 \\
\hline Flow to the Ring, $\mathrm{kg} / \mathrm{s}$ & 0.13880 & \begin{tabular}{|l|}
0.15384 \\
\end{tabular} & 0.20291 & \begin{tabular}{|l|}
0.22179 \\
\end{tabular} \\
\hline Increase of production, \% & 0.0 & 10.83 & 0.0 & 9.3 \\
\hline
\end{tabular}

It must be understood that the potential increase of production due to JT valve replacement with an expansion engine is a relative number, which is dependent upon the base conditions. The production increase due to JT replacement with a wet engine at present conditions and for 3compressors flow is $\sim 9.3 \%$. Nevertheless, the calculations show that if the coldbox production is routed into a low pressure dewar at 33 psia, and wet expander efficiency is $65 \%$, then the increase of production (WE vs. JT) is $10.8 \%$. The coldbox inlet pressure is another contributor, i.e. higher the inlet pressure, greater the expected increase of production. The calculations show that if CHL coldbox 
is operated at 1.310 MPa inlet pressure (instead of present $1.1376 \mathrm{MPa}$ ) then the expected increase of production (WE vs. JT) would constitute another $1.5 \%$. But the single greatest contributor to the effect of JT replacement with expander is a coldbox performance at initial conditions, e.g. how close the coldbox thermodynamic efficiency to the Carnot efficiency. If a coldbox is designed and operated far below its optimum for a given set of inlet/outlet conditions, then such a replacement would produce a greater relative increase of production than for an optimized coldbox. Therefore the increase of production as much as $28 \%$ reported in [5] should be understood in this context.

\section{SUMMARY}

A mathematical model based on a finite element approach has been developed to simulate the thermo- and gas-dynamic processes for the equipment included in a helium coldbox. The model provides for high accuracy and conversion stability. Though the cocfficients used in thermo- and gasdynamic equations are unique for the given coldbox, the general approach, the equations, the methods of computations, and most of the subroutines written in FORTRAN can be readily applied to different coldboxes. The simulation results are compared against actual operating data to demonstrate applicability of the model.

\section{REFERENCES}

1. C.H.Rode, Tevatron cryogenic system, "The Proceedings of the 12th International Conference on High Energy Accelerators" (1983).

2. G.A.Hodge, et al, Recent operating experience with the Fermilab Central Helium Liquefier, "Advances in Cryogenic Engineering" Vol.29, (1984).

3. R.J.Walker, et al, Recent operating experience with the Fermilab Central Helium Liquefier, "Advances in Cryogenic Engineering" Vol.31, (1986).

4. J.N.Makara, et al, Fermilab Central Helium Liquefier Upgrade, "Advances in Cryogenic Engineering" Vol.39A, (1994).

5. Venkatarao Ganni, et al, Capacity Upgrade of the Exell Helium Liquefier Plant by the Addition of a Wet Engine, “Advances in Cryogenic Engineering” Vol.31, (1985). 